\title{
Changes within oribatid mite communities associated with Scots pine regeneration
}

\author{
Jane A. Horwood and Kevin R. Butt
}

\begin{abstract}
Horwood, J. A. and Butt, K. R. 2000. Changes within oribatid mite communities
\end{abstract} associated with Scots pine regeneration. - Web Ecol. 1: 76-81.

\begin{abstract}
Compositions of oribatid mite communities were compared under five stages of native Scots pine regeneration (spanning $100 \mathrm{yr}$ ) within the Abernethy Forest Reserve, U.K. Sampling was conducted during autumn and spring, and oribatid mites identified using the morphospecies technique. Results showed the oribatid mite fauna to be abundant and diverse. Density of mites generally decreased with soil depth, however in the woodland sites the upper $10 \mathrm{~cm}$ of soil contained more individuals than the litter layer. Eleven morphospecies showed significant differences $(\mathrm{p}<0.05)$ in abundance between sites, with marked preferences shown for either mature woodland or tree-less moorland. During spring, morphospecies richness and mite density were highest at the woodland sites, but during autumn they were greater at the moorland sites. Shannon Wiener diversity indices and measures of evenness, calculated for each site, showed that despite having a high morphospecies richness, sites were often dominated by a few very abundant morphospecies. A greater number of mites were collected during autumn, but only one morphospecies showed significant seasonal differences in numbers. Factors influencing differences in oribatid communities at each site are discussed and the use of morphospecies as an identification tool is also assessed.
\end{abstract}

J.A.Horwood (jh319@cam.ac.uk) and K.R.Butt, Dept of Environmental Management, The Univ. of Central Lancashire, Preston, U.K. PR1 2 HE.

Oribatid mites are generally the most abundant and diverse arthropod group in forest soils. They are instrumental in the decomposition of organic matter and turnover of nutrients and therefore directly influence the productivity of plant communities (Swift et al. 1979). Hogervorst et al. (1993) showed a significant positive correlation between oribatid mite species and the vitality of a Scots pine Pinus sylvestris L. forest whilst Van Straalen et al. (1988) identified oribatids as indicators for monitoring changes in soil quality. However, before the role of oribatids in a specific habitat can be understood, a knowledge of factors influencing their population dynamics is required.
Seasonal fluctuations and the vertical distribution of oribatid mites are well documented (Block 1966, Usher 1975, Badejo 1990). The influence of vegetation or soil type on oribatid communities has also been examined (Curry 1978, Hagvar 1984, Schaefer and Schauermann 1990, Battigelli et al. 1994), but few have assessed the effect of stand age (Migge et al. 1998).

Little work, except that of Usher (1975), has been conducted on oribatid mite communities of Scots pine woodlands in the U.K. Plans are underway to extend the range of this habitat (Kelly 1996) and the effects of such a woodland expansion on birds, mammals and above ground in- 
vertebrates have been investigated (Bunce and Jeffers 1975, Aldhous 1994), but little consideration has been given to any soil invertebrates. The aim of this research was therefore to compare oribatid mite communities across a series of sites thought to represent different stages of Scots pine regeneration. These comprised of moorland, mature Scots pine woodland and a number of stands of intermediate age. The seasonal and vertical movements of oribatids were also considered.

\section{Study site and methods}

The study was conducted near Loch Garten in the Abernethy Forest Reserve, Scotland (National Grid Reference NH 970170). The reserve comprises an area of 12800 ha of which 1930 ha is native Scots pine woodland. This area contains the largest remnant of Caledonian pinewood in the U.K. The woodland understorey is dominated by Calluna vulgaris (L.) and Vaccinium spp. whilst on adjacent moorland Sphagnum spp. and Eriophorum spp. are also present. The site has an elevation of $230 \mathrm{~m}$, mean monthly temperatures in the range $1.9-10.0^{\circ} \mathrm{C}$ and mean monthly rainfall of $70 \mathrm{~mm}$. The soil is dystrophic peat $(\mathrm{pH} 3.8-5.3)$ derived from schists and gneisses of the Moine series. In general, these are of low inherent fertility, with a scarcity of all nutrients, especially phosphorous.

Sampling sites, as follows, were established based on tree density, diameter at breast height and age: 1) moorland dominated by $C$. vulgaris, no Scots pine regeneration. 2) Regeneration 1 (R1) age $8 \mathrm{yr}$, diameter at breast height (dbh) $5 \mathrm{~cm}$ and density 9000 trees ha ${ }^{-1}$. 3) Regeneration 2 (R2) age $20 \mathrm{yr}, \mathrm{dbh} 25 \mathrm{~cm}$ and density 3500 trees ha $^{-1}$. 4) Regeneration 3 (R3) age $65 \mathrm{yr}$, dbh $61 \mathrm{~cm}$ and density 800 trees $\mathrm{ha}^{-1}$ and 5) woodland age $100 \mathrm{yr}, \mathrm{dbh} 155 \mathrm{~cm}$ and density 300 trees ha ${ }^{-1}$.

At each site a plot of $20 \times 20 \mathrm{~m}$ was set up from which soil samples were randomly taken. Sites were sampled during autumn 1998 and spring 1999. Soil cores of diameter $5 \mathrm{~cm}$ and depth $10 \mathrm{~cm}$ were taken and subdivided into litter and depths of $0-5 \mathrm{~cm}$ and $5-10 \mathrm{~cm}$. Invertebrates were extracted in Tullgren funnels over $48 \mathrm{~h}$ and stored in $70 \%$ ethanol. Oribatid mites were separated to "morphospecies" using simple morphological differences (Oliver and Beattie 1996, Osler and Beattie 1999). Counts of oribatids from core samples were expressed as number $\mathrm{m}^{-2}$. Due to the aggregated distribution of oribatid mites non-parametric analytical methods were utilised. A Kruskal-Wallis ANOVA was therefore used to examine morphospecies differences between sites and season.

Diversity of soil animals was calculated using the Shannon-Wiener index $(H) ; H=-\sum p_{i} \ln p_{i}$ (where $p_{i}$ is the proportion of each morphospecies in the community). The heterogeneity of morphospecies distribution was calculated as evenness (E); $\mathrm{E}=\mathrm{H} / \mathrm{ln} s$ (where $s=$ number of morphospecies per site).

\section{Results}

A total of 9271 oribatid mites $\left(94 \times 10^{3}\right.$ individuals $\left.\mathrm{m}^{-2}\right)$ representing 46 morphospecies were recorded from all five sites during autumn 1998 and spring 1999. The majority of samples were dominated by one morphospecies (Superfamily; Oppioidae) which comprised 23\% of the overall community and occurred at densities up to $54 \times$ $10^{3}$ individuals $\mathrm{m}^{-2}$. Table 1 lists the mean density of all morphospecies at each site during autumn and spring. It also summarises results for differences between site and season, applied to the twenty most abundant morphospecies.

\section{Vertical distribution}

Density of oribatid mites decreased with soil depth and this trend occurred even when $0-5 \mathrm{~cm}$ and $5-10 \mathrm{~cm}$ samples were taken from the same soil horizon. In total $55 \%$ of oribatid mites were present in the litter layer and 36\% at a depth of $0-5 \mathrm{~cm}$. Overall vertical distribution was very similar between seasons, but showed significant variation between regeneration sites $(\mathrm{p}<0.01)$. The proportion of mites in the litter layer was greatest at R2 during both seasons; $73 \%$ of total individuals during autumn and $79 \%$ during spring. The proportion of individuals in the litter layer declined between R2 and the mature Scots pine stand. Woodland supported the majority of individuals within the $0-5 \mathrm{~cm}$ layer; $48 \%$ of the total during autumn and $58 \%$ during spring. In both seasons this could mainly be attributed to an increase in one morphospecies (Morphospecies 4; Superfamily: Oppioidea).

\section{Variation between sites}

The distribution and abundance of oribatid morphospecies is shown in Table 1 . In total 32, 25, 31, 35 and 38 morphospecies occurred at the Moorland, R1, R2, R3 and Woodland sites respectively during the whole sampling period. The density of some morphospecies varied between sites with 11 showing significant differences $(\mathrm{p}<$ 0.05 ) in overall numbers. Seven morphospecies were restricted to the older stands of Scots pine (R3 or woodland) whilst 3 were restricted to the moorland or primary regeneration (R1), and 15 were found at all sites during both seasons. Differences were also apparent regarding the site at which the maximum density was reached. A number of morphospecies showed a marked preference for either the moorland or woodland end of the transect as shown by morphospecies 44 (Family Eremaeidae) (Fig. 1a, b) and morphospecies 19 (Steganacarus magnus Nicolet) (Fig. 1c, d) respectively. Others, such as morphospecies 13 (Hermannia spp.) (Fig. 1e, f) were present throughout all sites, but displayed elevated numbers at the mid point of 
Table 1. Mean population density (individuals $\times 10^{3} \mathrm{~m}^{-2}$ ) of oribatid morphospecies found at Loch Garten transect sites during autumn 1998 and spring 1999. (Mean densities given to the nearest integer. Mean values $<0.5$ represented by + and a zero value by - ). Also shown are non-parametric test results examining differences in the twenty most abundant morphospecies between sites during each season (site) and between seasons (season). A space indicates the analysis was not carried out. (*: differences significant at $\mathrm{p}<0.05,^{* *}$ : differences significant at $\mathrm{p}<0.01$, ns: no significant difference).

\begin{tabular}{|c|c|c|c|c|c|c|c|c|c|c|c|c|c|}
\hline \multirow{2}{*}{$\begin{array}{l}\text { Morpho } \\
\text { species } \\
\text { number }\end{array}$} & \multirow[b]{2}{*}{$\mathrm{M}$} & \multicolumn{4}{|c|}{ Autumn } & \multicolumn{8}{|c|}{ Spring } \\
\hline & & $\mathrm{R} 1$ & $\mathrm{R} 2$ & R3 & W & site & M & $\mathrm{R} 1$ & $\mathrm{R} 2$ & R3 & W & site & season \\
\hline 1 & 3 & 22 & 5 & 14 & 5 & ns & 6 & 12 & 3 & 7 & 14 & -- & $\mathrm{ns}$ \\
\hline 2 & - & - & + & + & 1 & & - & - & - & - & - & & \\
\hline 3 & + & - & - & 1 & 1 & & + & + & + & 1 & 1 & & \\
\hline 4 & 10 & 26 & 15 & 23 & 38 & $\mathrm{~ns}$ & 22 & 9 & 10 & 11 & 54 & $*$ & ns \\
\hline 5 & 1 & 3 & 1 & 4 & 2 & ns & 2 & 1 & + & 3 & 1 & -- & ns \\
\hline 6 & + & 1 & + & 2 & + & ns & 2 & 1 & + & 2 & + & -- & ns \\
\hline 8 & - & - & - & - & - & & - & - & - & - & + & & \\
\hline 9 & - & - & - & - & 1 & & - & - & - & - & + & & \\
\hline 10 & 1 & - & + & + & + & & - & - & - & 1 & + & & \\
\hline 11 & - & - & - & - & + & & - & - & - & + & - & & \\
\hline 12 & - & - & - & - & - & & - & - & - & + & + & & \\
\hline 13 & 5 & 4 & 43 & 4 & 4 & $*$ & 11 & 14 & 26 & 4 & 1 & $* *$ & ns \\
\hline 14 & 4 & 3 & 2 & 4 & 1 & ns & 4 & 6 & 1 & 1 & 8 & -- & ns \\
\hline 15 & 2 & 2 & 2 & 9 & 2 & $\mathrm{~ns}$ & 1 & 3 & 1 & 3 & 5 & -- & $\mathrm{ns}$ \\
\hline 16 & 4 & 5 & 1 & 5 & 1 & $\mathrm{~ns}$ & 6 & 10 & 2 & 2 & 2 & -- & ns \\
\hline 17 & 2 & 1 & + & - & - & & - & 1 & - & - & - & & \\
\hline 18 & + & 3 & 9 & 4 & 1 & $*$ & + & 2 & 1 & 1 & 1 & -- & ns \\
\hline 19 & + & 1 & 1 & 7 & 4 & $* *$ & + & 1 & 2 & 4 & 3 & $*$ & ns \\
\hline 20 & 3 & 3 & 2 & 3 & + & ns & 4 & 3 & 1 & 1 & 1 & -- & ns \\
\hline 21 & + & 4 & 10 & 6 & 14 & $* *$ & - & - & 1 & 2 & 2 & $*$ & $* *$ \\
\hline 22 & + & + & + & + & - & & + & - & - & + & + & & \\
\hline 23 & 4 & 6 & 29 & 4 & 5 & $*$ & 7 & 7 & 12 & 3 & 2 & $*$ & ns \\
\hline 24 & 1 & 6 & 2 & 5 & 6 & $*$ & 1 & 1 & 1 & 3 & 5 & $*$ & ns \\
\hline 25 & + & - & - & 1 & 1 & & + & - & + & 1 & 1 & & \\
\hline 26 & + & - & - & 1 & + & & - & - & - & 1 & 2 & & \\
\hline 27 & - & - & + & + & + & & - & - & - & - & 1 & & \\
\hline 28 & - & - & + & - & 1 & & + & - & - & - & 2 & & \\
\hline 29 & + & 4 & 11 & 3 & 2 & $*$ & 3 & 4 & 8 & 1 & 1 & $*$ & ns \\
\hline 32 & 9 & 13 & + & + & + & ns & 1 & 4 & - & + & + & -- & ns \\
\hline 33 & - & - & - & - & - & & - & - & - & - & + & & \\
\hline 34 & - & - & - & - & + & & - & - & - & - & - & & \\
\hline 35 & - & + & - & + & - & & - & + & - & + & + & & \\
\hline 37 & + & - & - & 1 & + & & - & - & 1 & 2 & 1 & & \\
\hline 38 & 1 & + & - & + & + & & - & + & - & - & 1 & & \\
\hline 39 & + & - & - & - & - & & - & - & - & - & - & & \\
\hline 40 & + & + & 1 & 2 & 1 & $*$ & - & - & + & 1 & 2 & ** & ns \\
\hline 41 & - & - & - & - & 1 & & - & - & - & + & 2 & & \\
\hline 42 & - & - & + & - & + & & - & - & - & + & + & & \\
\hline 43 & 2 & 1 & + & 1 & 1 & $\mathrm{~ns}$ & 1 & 1 & + & 1 & 1 & -- & ns \\
\hline 44 & 2 & 7 & 12 & 1 & - & $*$ & 5 & 9 & 10 & + & - & $* *$ & ns \\
\hline 45 & - & - & + & - & - & & - & - & - & - & - & & \\
\hline 46 & 8 & - & - & - & - & $*$ & - & - & - & - & - & -- & $\mathrm{ns}$ \\
\hline 47 & - & - & - & + & - & & - & - & - & - & - & & \\
\hline 48 & 1 & - & - & - & - & & 1 & 1 & - & - & + & & \\
\hline 49 & 1 & - & - & - & - & & - & - & - & - & - & & \\
\hline 50 & - & - & - & - & - & & - & - & - & + & - & & \\
\hline
\end{tabular}


a. Autumn

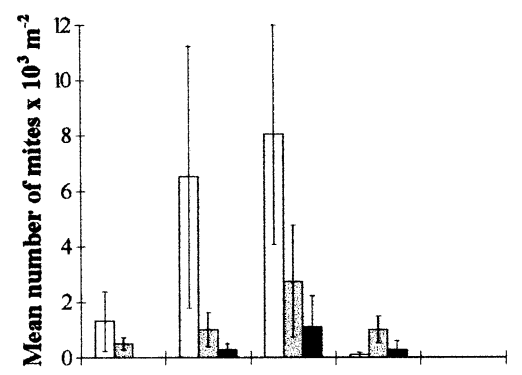

b. Spring

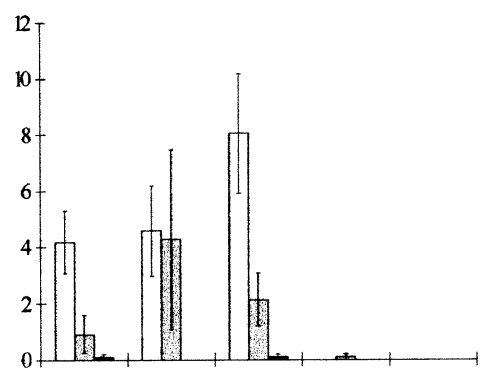

\section{MORPHOSPECIES 19}

(Steganacarus magnus)
c. Autumn
d. Spring
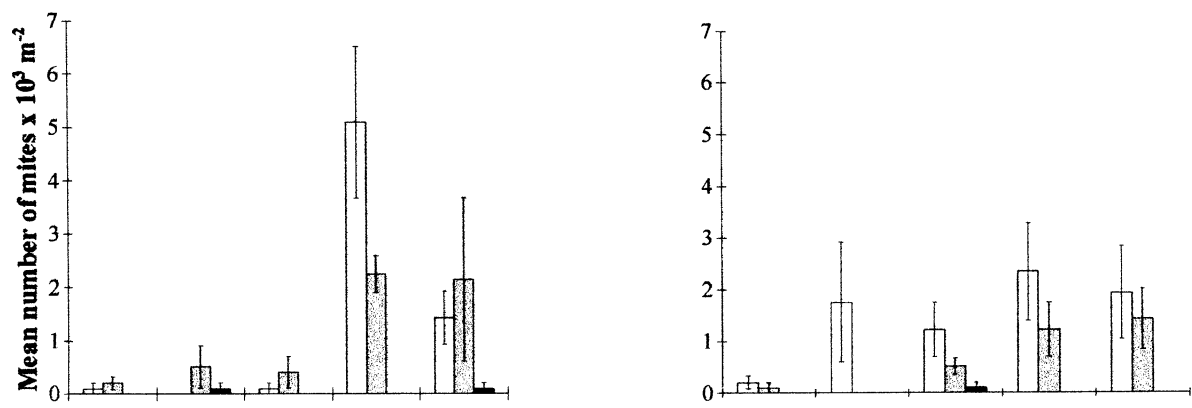

\section{MORPHOSPECIES 13}

(Family Eremaeidae)

e. Autumn

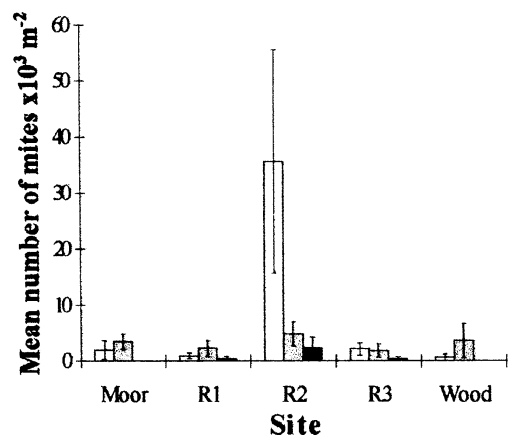

f. Spring

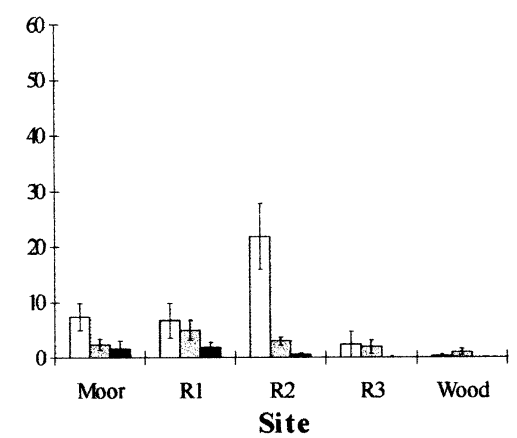

Fig. 1. The mean density of morphospecies 44 (HermanniaI spp.) (a and b), morphospecies 19 (Steganacuarus magnus) (c and d) and morphospecies 13 (Family Eremaeidae) (e and f) at all Loch Garten transect sites during 1998 and 1999. (: litter; : 0-5 cm; and $\mathbf{~}$ $5-10 \mathrm{~cm})$. 
the transect (R2). These distribution patterns were similar during each season.

The variations in mean density of mites, morphospecies richness and diversity between sites are shown in Table 2 . Morphospecies richness was greater during autumn compared with spring at the moorland end of the transect (moor, R1 and R2), but at the woodland end morphospecies richness was as high, or higher during spring. During autumn the lowest species richness (25) was found at the mid regeneration point (R2) despite this site supporting the highest mean density of mites $\left(147 \times 10^{3}\right.$ individuals). During both seasons the Shannon-Wiener diversity indices were highest at the oldest regeneration site (R3).

\section{Seasonal variation}

A total of 5172 oribatid mites were collected during autumn compared with 4099 during spring. A maximum mean density of $147 \times 10^{3}$ individuals $\mathrm{m}^{-2}$ was reached during autumn at R2, but by spring this had almost halved and greatest numbers were present within the woodland $\left(115 \times 10^{3}\right.$ individuals $\left.\mathrm{m}^{2}\right)$. Morphospecies 21 was the only morphospecies to show significant seasonal differences $(\mathrm{p}<0.01)$ with abundance being greater in autumn than in spring.

\section{Discussion}

The results show that the oribatid mite fauna within the sampled area of the Abernethy Forest Reserve is both abundant and diverse. The mean density of mites was similar to those found under Scots pine by Hogervorst et al. (1993) who reported mean densities of up to $100 \times 10^{3}$ individuals $\mathrm{m}^{-2}$. These high densities, compared to deciduous woodlands, are in part attributable to the high content of organic matter present. This creates an environment with increased pore volume and moisture content which both lead to elevated mite densities (Banerjee and Sanyal 1991).
The decrease in density of oribatids with increasing depth, is widely reported within both woodland and moorland soils (Wallwork 1959, Wood 1967, Berg et al. 1998, Migge et al. 1998). The decrease in numbers at greater depths is probably due to the influence of soil moisture, temperature and food resources. However the sampling periods excluded cold winters or dry summers when mites may move to deeper soil layers. The density of oribatid mites increased in deeper soil layers under older woodland, something also reported by Migge et al. (1998) who suggested this may be due to an increase in food resources as tree stands develop.

A number of morphospecies showed differences in density between sites. Not all morphospecies reached their maximum recorded density at the same site, which may be attributable to changes in vegetation along the time series. Microphytophagous oribatids may be influenced by the presence or absence of microorganisms, associated with changes in vegetation. For example, morphospecies present only at the moorland end of the transect, such as morphospecies 44, may be dependant upon microflora associated with Eriophorum spp. which were not present under mature woodland. Equally macrophytophagous oribatids may show distributions related to vegetation. The juveniles of S. magnus (morphospecies 19), often feed inside decomposing pine cones (Webb 1991). Their paucity at moorland sites may therefore be explained by their preference for sites with pine cone litter.

Differences in diversity and evenness values between sites may, in part, have been due to the dominance of a few morphospecies. For example, during spring the woodland site had a low evenness value due to the dominance of morphospecies 4 , which accounted for $47 \%$ of individuals, whilst at R2 low evenness and diversity values were due to the dominance of morphospecies 13 .

The use of morphospecies has enabled an estimation of diversity which without taxonomic training would otherwise have been impossible. However since this technique uses differences in external morphology the actual number of species may have been over- or under-estimated. Adults, larval and nymphal stages of the same species may have

Table 2. Morphospecies richness, density, diversity and heterogeneity of morphospecies distribution (evenness) of oribatid mites from Loch Garten transect sites during autumn 1998 and spring 1999.

\begin{tabular}{|c|c|c|c|c|c|c|c|c|}
\hline & \multicolumn{2}{|c|}{ Morphospecies richness } & \multicolumn{2}{|c|}{$\begin{array}{l}\text { Mean number of } \\
\text { mites } \times 10^{3} \mathrm{~m}^{-2}\end{array}$} & \multicolumn{2}{|c|}{$\begin{array}{l}\text { Shannon-Weiner } \\
\text { diversity }\end{array}$} & \multicolumn{2}{|c|}{ Evenness } \\
\hline & Autumn & Spring & Autumn & Spring & Autumn & Spring & Autumn & Spring \\
\hline Moor & 29 & 21 & 66 & 75 & 2.72 & 2.42 & 0.81 & 0.79 \\
\hline $\mathrm{R} 1$ & 30 & 22 & 116 & 92 & 2.29 & 2.66 & 0.67 & 0.86 \\
\hline $\mathrm{R} 2$ & 25 & 17 & 147 & 80 & 2.22 & 1.87 & 0.69 & 0.66 \\
\hline $\mathrm{R} 3$ & 30 & 30 & 103 & 55 & 2.74 & 2.83 & 0.81 & 0.83 \\
\hline Wood & 30 & 36 & 95 & 115 & 2.19 & 2.21 & 0.64 & 0.62 \\
\hline
\end{tabular}


been recorded as different morphospecies, but equally a number of morphologically similar species of mites may have been "lumped" together. For example, a number of species from the Superfamily: Oppioidea could not be separated at this level of identification and have therefore been combined as "morphospecies 4". Although morphospecies richness was, in general, similar or higher in woodland soils, compared with the moorland end of the transect, diversity was lower. This contrasts with Migge et al. (1998) who reported that oribatid mite diversity was, in general, higher in $120 \mathrm{yr}$ old stands of Norway spruce Picea abies (L.) Karst. and beech Fagus sylvatica L. compared with 30 yr old stands. The development of Scots pine at Abernethy appears to be cyclical and all sites may once have supported mature woodland, as management of the site has occurred in the past. Vaccinium covered tree stumps from this time still remain on the moorland and therefore some mite species may still be present within the soil associated with these remnants. If this is so, mite numbers at the moorland and young regeneration sites may be enhanced compared with an area of moorland which may never have previously supported woodland.

In general, Oribatids did not show significant differences in density between autumn and spring, but seasonal fluctuations cannot be ruled out. Had sampling occurred on a more regular basis population maxima and minima such as those reported by Berg et al. (1998) may have occurred. In temperate pine forests, Crossley and Bohnsack (1960) and Usher (1975) both noted that although individual species of oribatids showed population maxima these were not synchronised and, on the whole, the total population was in both cases numerically stable.

The complexity of the soil environment and other microflora and fauna make it difficult to consider all variables which may influence mite distribution. However this study has shown that differences are present in the morphospecies composition of oribatid mite communities under Scots pine stands in different stages of regeneration.

Acknowledgements - Many thanks to the RSPB for allowing me access to their Abernethy Forest Reserve.

\section{References}

Aldhous, J. R. 1994. Our pinewood heritage proceedings. - Forestry Commission, Royal Society for the Protection of Birds and Scottish Natural Heritage.

Badejo, M. A. 1990. Seasonal abundance of soil mites (Acarina) in two contrasting environments. - Biotropica 22: 382-390.

Banerjee, S. and Sanyal, A. K. 1991. Oribatid mites as indicator of soil organic matter. - In: Veeresh, G. K., Rajagopal, D. and Viraktamath, C. A. (eds), Advances in management and conservation of soil fauna. Oxford and IBH Publishing Co., pp. $877-880$.
Battigelli, J. P., Berch, S. M. and Marshall, V. G. 1994. Soil fauna communities in two distinct but adjacent forest types on northern Vancouver Island, British Columbia. - Can. J. For. Res. 24: 1557-1566.

Berg, M. P. et al. 1998. Dynamics and stratification of functional groups of micro- and mesoarthropods in the organic layer of a Scots pine forest. - Biol. Fertil. Soils 26: 268-284.

Block, W. C. 1966. The distribution of soil Acarina on eroding blanket bog. -Pedobiologia 6: 27-34.

Bunce, R. G. H. and Jeffers, J. N. R. 1975. Native pinewoods of Scotland, N.E.R.C. symposium. - Institute of Terrestrial Ecology.

Crossley, D. A. and Bohnsack, K. K. 1960. Long term ecological study in the oak ridge area III: the oribatid fauna in pine litter. - Ecology 41: 628-638.

Curry, J. P. 1978. Relationships between microarthropod communities and soil and vegetational types. - Sci. Proc., Royal Dublin Soc. Ser. A 6: 131-141.

Hagvar, S. 1984. Six common mite species (Acari) in Norwegian coniferous soils: Relations to vegetation types and soil characteristics. - Pedobiologia 27: 355-364.

Hogervorst, R. F., Verhoeff, H. A. and van Straalen, N. M. 1993. Five year trends in soil arthropod densities in pine forests with various levels of vitality. - Biol. and Fertil. Soils 15: 189-195.

Kelly, B. 1996. Guest editorial. - Scotland's Environment Matters 1: 1-2.

Migge, S. et al. 1998. The oribatid mite community (Acarina) of pure and mixed stands of beech (Fagus sylvatica) and spruce (Picea abies) of different age. - Appl. Soil Ecol. 9: 115-121.

Oliver, I. and Beattie, A. J. 1996. Invertebrate morphospecies as surrogates for species: a case study. - Conserv. Biol. 101: 99109.

Osler, G. H. R. and Beattie, A. J. 1999. Relationships between body length, number of species and species abundance in soil mites and beetles. - Pedobiologia 43: 401-412.

Schaefer, M. and Schauermann, J. 1990. The soil fauna of beech forests: comparison between a mull and a moder soil. - Pedobiologia 34: 299-314.

Swift, M. J., Heal, W. O. and Anderson, J. M. 1979. Decomposition in terrestrial ecosystems. - Univ. California Press.

Usher, M. B. 1975. Seasonal and vertical distribution of soil arthropods: Cryptostigmata. - Pedobiologia 15: 364-374.

Van Straalen N. M, Kraak, M. H. S. and Denneman, C. A. J. 1988. Soil microarthropods as indicators of soil acidification and forest decline in the Veluwe area, the Netherlands. Pedobiologia 32: 47-55.

Wallwork, J. A. 1959. The distribution and dynamics of some forest soil mites. -Ecology 40: 557-563.

Webb, N. R. 1991. The role of Steganacarus magnus (Acari: Cryptostigmata) in the decomposition of the cones of Scots pine, Pinus sylvestris. - Pedobiologia 35: 351-359.

Wood, T. G. 1967. Acari and collembola of moorland soils from Yorkshire, England II: vertical distribution in four grassland soils. - Oikos 18: 137-140. 